\title{
Biodegradation of 2, 4-Dichlorophenol at Low Concentration and Specific Growth Rate of Pseudomonas sp. Strain DP-4
}

\author{
Mitsunori Tarao, Koichiro Tsunozaki and Masayuki Seto \\ Faculty of Agriculture, Tokyo University of Agric. \& Tech., Saiwaicho, Fuchu, Tokyo 183, \\ Japan
}

(Received July 15, 1993- Accepted October 1, 1993)

\begin{abstract}
In a pure culture of Pseudomonas sp. strain DP-4, a 2, 4-dichlorophenol (DCP)-assimilator, $10^{2} \mathrm{cell} / \mathrm{ml}$ of DP-4 increased to $10^{6} \mathrm{cell} / \mathrm{ml}$ at the early stationary phase in a mineral salts medium to which no organic substrates were deliberately added. This increase was attributable to the expense of ca. $2 \mu \mathrm{g} \mathrm{C} / \mathrm{ml}$ of contaminated organic substrates in the medium. In the culture of DP-4 with ca. $10^{6} \mathrm{cell} / \mathrm{ml}$ of the heterotrophic microorganisms which were no DCP-degraders, the density of DP-4 did not increase in the mineral salts medium without DCP, and when DCP was added the density of DP-4 increased with the the concentration of DCP. In the DP-4 culture with the heterotrophic microorganisms, the specific growth rates $(\mu)$ of DP-4 were measured at various concentrations of DCP in the range $0.01-10 \mu \mathrm{g} \mathrm{C} / \mathrm{ml}$, and $\mu$ of DP-4 was fitted to Monod's equation. The maximum specific growth rate $(3.2 /$ day $)$ and the half saturation constant $(0.11 \mu \mathrm{g} \mathrm{DCP}-\mathrm{C} / \mathrm{ml})$ were considered as kinetic parameters when DP-4 assimilated DCP as a sole source of carbon.
\end{abstract}

Key words : Specific growth rate, low concentration, biodegradation, contaminated organic substrate, 2, 4-dichlorophenol

\section{Introduction}

Parameters on the growth kinetics of microorganisms such as specific growth rate $(\mu)$ and half saturation constant $\left(\mathrm{K}_{\mathrm{s}}\right)$ are indispensable for the analysis of nutrient utilization by microorganisms $^{7,13)}$. According to Monod's equation ${ }^{8)}$, the specific growth rate varies with the concentration of growth-limiting substrates. That is,

$$
\mu=\frac{\mu_{\max } \mathrm{S}}{\mathrm{K}_{\mathrm{S}}+\mathrm{S}}
$$

where $\mu=\mathrm{dB} / \mathrm{dt}(1 / \mathrm{B})$ is the specific growth rate, $\mu_{\max }$ is the maximum specific growth rate obtained in the absence of any substrate limitation, $\mathrm{S}$ is the concentration of the growth-limiting substrate, $\mathrm{K}_{\mathrm{s}}$ is a half saturation constant which is defined as the concentration of growth-limiting substrate which allows the microorganisms to grow at half the maximum specific growth rate, and B is the population density. However, determining these kinetic parameters is sometimes difficult, especially when a low concentration of organic substrate is used as a growth-limiting substrate. For example, if a synthetic liquid medium to which no organic substrates has been deliberately added is contaminated with uncharacterized organic substrates ${ }^{4)}$ as impurities present in the mineral salts, adhered to glassware or invasion from air, microorganisms assimilate not only the organic substrate added but also contaminated organic substrates. Therefore, bacterial growth will reflect the combined influence of added organic substrate and uncharacterized organic substrates rather than the effects of added substrate alone ${ }^{9)}$. Thus, heterotrophic bacteria, whose initial density was $10 \mathrm{cell} / \mathrm{ml}$, could grow to $10^{6} \mathrm{cell} / \mathrm{ml}$ at the expense of contaminated organic substrates which can be found even in the double 
distilled water ${ }^{12)}$.

In this study, we tried to eliminate contaminated organic substrates by using heterotrophic microorganisms, and also tried to estimate kinetic parameters such as $\mu$ and $\mathrm{K}_{\mathrm{s}}$ of Pseudomonas sp. strain DP-4 $4^{11)}$ a 2, 4-dichlorophenol (DCP)assimilator, in a culture where a low concentration of DCP was considered to be the sole source of carbon and energy.

\section{Materials and Methods}

The growth of DP-4 on the low concentration of DCP was studied in a diluted mineral solution (D-MS) medium with or without heterotrophic microorganisms. DP-4 is able to grow at the expense of DCP as the sole source of carbon and energy. The heterotrophic microorganisms, which grew in a tank in which deionized water was stored, were used to eliminate the contaminated organic substrates. It was ascertained by a preliminary study that they were composed of several uncharacterized species and none of species were DCP-degraders. Either DP-4 or the heterotrophic microorganisms were pre-cultured in sterilized deionized water for 4 to 5 days before inoculation. Some suspensions of the heterotrophic microorganisms in $3 \mathrm{ml}$ of the pre-cultured deionized water were inoculated to $300 \mathrm{ml}$ of sterilized D-MS medium in $500 \mathrm{ml}$ screwcapped Erlenmeyer flasks and incubated for 4 to 5 days, and some were not inoculated. During this incubation period, the initial density of the heterotrophic microorganisms at ca. $10^{4} \mathrm{cell} / \mathrm{ml}$ increased to ca. $10^{6} \mathrm{cell} / \mathrm{ml}$. Since this density was invariable, even after incubation for an additional 1 or 2 months, the culture was considered to be at the stationary phase, indicating that most of the contaminated orgamic substrates had been eliminated. Then, the desired amount of DCP and DP-4 suspension, which was diluted with sterilized deionized water, were inoculated. The time course of the concentration of remaining DCP and density of DP-4 were measured. The cultures were incubated aerobical- ly at $25^{\circ} \mathrm{C}$ in the dark.

The D-MS medium contained : $2.1 \mu \mathrm{M}$ $\mathrm{Na}_{2} \mathrm{HPO}_{4}, 0.9 \mu \mathrm{M} \mathrm{KH_{2 }} \mathrm{PO}_{4}, 40 \mu \mathrm{M} \mathrm{NH} \mathrm{NO}_{3}, 10$ $\mu \mathrm{M} \quad \mathrm{MgSO}_{4} \cdot 7 \mathrm{H}_{2} \mathrm{O}, 10 \mu \mathrm{M} \quad \mathrm{CaCl}_{2} \cdot 2 \mathrm{H}_{2} \mathrm{O}, 3 \mu \mathrm{M}$ $\mathrm{Na}_{2} \mathrm{SiO}_{3}, 1 \mu \mathrm{M} \mathrm{MnCl}_{2} \bullet 4 \mathrm{H}_{2} \mathrm{O}, 1 \mu \mathrm{M} \mathrm{H}_{3} \mathrm{BO}_{3}, 1 \mu \mathrm{M}$ $\mathrm{Na}_{2} \mathrm{MoO}_{4} \cdot 2 \mathrm{H}_{2} \mathrm{O}, \quad 5 \mathrm{nM} \quad \mathrm{FeCl}_{3} \cdot 6 \mathrm{H}_{2} \mathrm{O}, \quad 5 \mathrm{nM}$ $\mathrm{CuSO}_{4} \cdot 5 \mathrm{H}_{2} \mathrm{O}, 5 \mathrm{nM} \quad \mathrm{ZnSO}_{4} \cdot 7 \mathrm{H}_{2} \mathrm{O}$ and $5 \mathrm{nM}$ $\mathrm{CoSO}_{4} \cdot 7 \mathrm{H}_{2} \mathrm{O}$. The $\mathrm{pH}$ was 7.0. The D-MS medium was prepared with deionized water that had been passed through the ion exchange resin (ORGANO Co., Ltd. MB-3). The concentration of remaining DCP was analyzed by HPLC (Yanagimoto Co., Ltd L-4000 W) ${ }^{10}$. When the concentration of DCP was less than $0.01 \mu \mathrm{g} \mathrm{C} / \mathrm{ml}$, DCP in a $25-\mathrm{ml}$ portion of subsample of the culture was concentrated with a Sep-pak cartridge (Millipore Corp., Sep-pak ${ }^{\circledR}$ plus tC18 cartridge) to a $2.5 \mathrm{ml}$ of sample. The density of heterotrophic microorganisms were estimated by the colony forming unit ( $\mathrm{CFU}$ ) method. The medium for $\mathrm{CFU}$ contained $0.7 \mathrm{mg}$ of nutrient agar (Eiken Co., Ltd.) and $8 \mathrm{mg}$ of agar per $\mathrm{ml}$ of deionized water. The density of DP-4 was estimated by the most probable number (MPN) method $^{10)}$ using a D-MS medium containing $10 \mu \mathrm{g}$ DCP-C $/ \mathrm{ml}$. Subsamples of the culture in the flasks were diluted with sterilized deionized water by 10 -fold serial solution. One $\mathrm{ml}$ portion of the solution was inoculated into $10 \mathrm{ml}$ of the D-MS medium containing DCP. All tubes were incubated aerobically at $25^{\circ} \mathrm{C}$ in the dark for 2 weeks. Disappearance of DCP in tube after 2 weeks, as measured by HPLC, was defined as a positive indication of the presence of DP-4.

The specific growth rate of DP-4 was determined as follows ${ }^{2}$.

$$
\mu \mathrm{t}=2.303\left(\log \mathrm{X}-\log \mathrm{X}_{0}\right)
$$

where $t$ was time in the linear phase of the growth curve which exhibited as semi-log plot, and $X_{0}$ and $X$ were the initial and final densities of DP-4, respectively, estimated in that phase. $\mathrm{K}_{\mathrm{s}}$ or $\mu_{\max }$ was determined statistically from equation (1), that is, 


$$
\frac{1}{\mu}=\frac{1}{\mathrm{~S}} \cdot \frac{\mathrm{K}_{\mathrm{s}}}{\mu_{\max }}+\frac{1}{\mu_{\max }}
$$

which is analogous to the Lineweaver-Burk equation.

\section{Results}

In the absence of heterotrophic microorganisms, DP-4 degraded all DCP, except for $0.01 \mu \mathrm{g}$ DCP$\mathrm{C} / \mathrm{ml}$ (Fig. 1(A)). Since the growth curves of DP-4 were almost identical irrespective of the concentration of DCP (Fig. 1 (B)), it was suggest-



Fig. 1. Degradations of DCP (A) and density changes of DP-4 (B) in the absence of heterotrophic microorganisms. Initial concentrations of

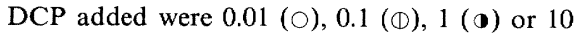
(•) $\mu \mathrm{g} \mathrm{C} / \mathrm{ml}$. ed that the DP-4 grew at the expense of not only DCP but also contaminated organic substrates.

In the absence of heterotrophic microorganisms, the density of DP-4 increased from $1.8 \times 10^{2}$ to $3.6 \times 10^{5} \mathrm{cell} / \mathrm{ml}$ in the medium to which no organic substrates were deliberately added (Fig. 2). While, in the presence of heterotrophic microorganisms, the density of DP-4 did not increase. The density of heterotrophic microorganisms was almost constant at $10^{6} \mathrm{cell} / \mathrm{ml}$ (data not shown). The growth of DP-4 in the absence of heterotrophic microorganisms was attributable to the expense of contaminated organic substrates in the medium, whereas in the presence of microbial community, elimination of contaminated organic substrates by heterotrophic microorganisms was evident.

In the presence of heterotrophic microorganisms, DP-4 degraded all DCP, except for $0.01 \mu \mathrm{g}$ DCPC/ml (Fig. 3(A)). Since the growth of DP-4 was not observed without degradation of DCP at 0.01



Fig. 2. Density changes of DP-4 in D-MS medium without DCP in the absence $(O)$ or presence $(\bullet)$ of heterotrophic microorganisms. 


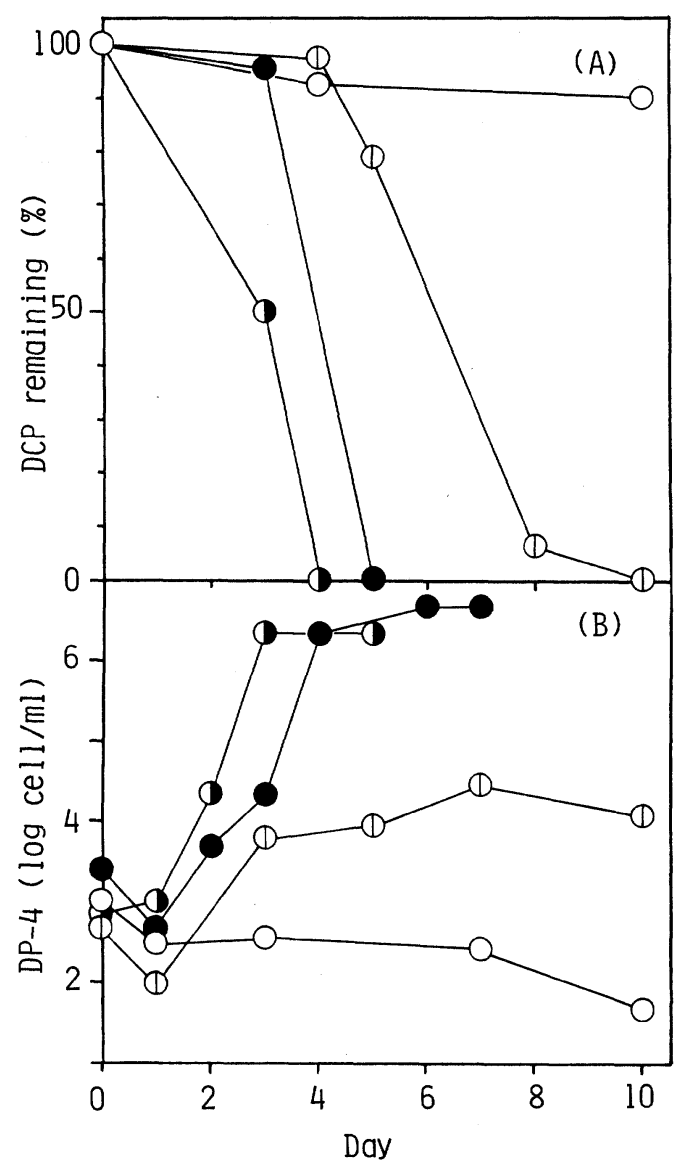

Fig. 3. Degradations of DCP (A) and density changes of DP-4 (B) in the presence of heterotrophic microorganisms. Symbols are the same as Fig. 1.

$\mu \mathrm{g}$ DCP-C $/ \mathrm{ml}$, and since higher densities of DP-4 at the stationary phases were observed when higher concentrations of DCP were degraded (Fig. 3(B)), it was suggested that DP-4 grew not at the expense of contaminated organic substrates but at the expense of DCP. The densities of heterotrophic microorganisms were ca. $10^{6} \mathrm{cell} / \mathrm{ml}$ during incubation (data not shown).

The relations between the initial concentrations of DCP added and the densities of DP-4 in the early stationary phase are shown in Fig. 4. In the absence of heterotrophic microorganisms, the densities of DP-4 were consistently $2.0 \times 10^{6} \mathrm{cell} / \mathrm{ml}$,



Fig. 4. Relations between initial concentrations of DCP and the densities of DP-4 in the early stationary phase in the absence $(O)$ or presence (•) of heterotrophic microorganisms.

irrespective of the concentration of DCP. While, in the presence of heterotrophic microorganisms, the density of DP-4 at the time when DCP was almost degraded seemed proportional to the initial concentrations of DCP except when 0.1 or $10 \mu \mathrm{g}$ $\mathrm{DCP}-\mathrm{C} / \mathrm{ml}$ was added.

The relations between the initial concentrations of DCP and the specific growth rate $(\mu)$ of DP-4 were obtained from data shown in Figs. 1 and 3 and other data not shown in these figures (Fig. 5). The $\mu$ of DP-4 was determined in the linear phase of the growth curve which is depicted as a semi-log plot. For example, the $\mu$ of DP-4 grown at $1 \mu \mathrm{g}$ $\mathrm{DCP}-\mathrm{C} / \mathrm{ml}$ in the presence of heterotrophic microorganisms was calculated as follows. The densities of DP-4 at 1,2 and 3 days after inoculation were $9.3 \times 10^{2}, \quad 2.3 \times 10^{4}$ and $2.3 \times 10^{6} \mathrm{cell} / \mathrm{ml}$, respectively. The $\mu$ of DP-4 was calculated by using equation (2) from the straight line of these data as determined by a method of least squares. In the absence of heterotrophic microorganisms, the $\mu$ were almost constant at ca. 5.0/day, irrespective of the concentration of DCP, except for 10 $\mu \mathrm{g} \mathrm{DCP}-\mathrm{C} / \mathrm{ml}$ whose $\mu$ was $3.2 /$ day. While, in 


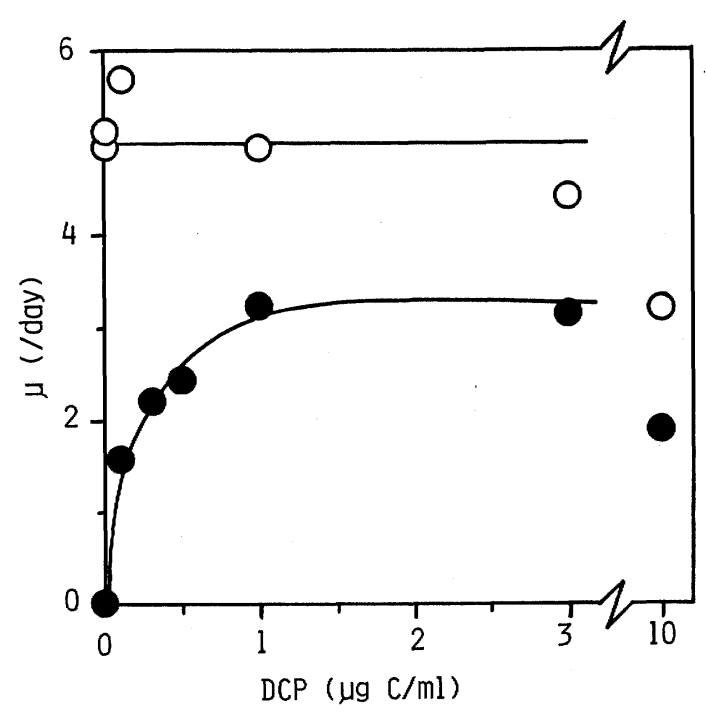

Fig. 5. Relations between initial concentrations of DCP and the specific growth rates $(\mu)$ of DP-4 in the absence $(O)$ or presence $(\bullet)$ of heterotrophic microorganisms.

the presence of heterotrophic microorganisms, the $\mu$ increased with the increase of the initial concentrations of DCP up to $1 \mu \mathrm{g} \mathrm{DCP-C} / \mathrm{ml}$. According to equation (3), relations between the reciprocal of the specific growth rate and that of initial concentrations of DCP, except for $10 \mu \mathrm{g}$ DCP-C/ $\mathrm{ml}$, were linear (data not shown) with a correlation coefficient of 0.974 . When DP-4 assimilated DCP as a sole source of carbon and energy, it was calculated from Monod's equation that the maximum specific growth rate $\left(\mu_{\max }\right)$ or $\mathrm{K}_{\mathrm{s}}$ was 3.2 /day or $0.11 \mu \mathrm{g} \mathrm{DCP}-\mathrm{C} / \mathrm{ml}$, respectively.

\section{Discussion}

The aim of this study was to determine the specific growth rate of DP-4 assimilating DCP at low concentrations. Monod's equation, described as equation (1), indicates that the $\mu$ of DP-4 should decrease with the concentration of DCP. However, since DP-4 assimilates contaminated organic substrates, the precise determination of $\mu$ of DP-4 at the expense of DCP was impossible
(Figs. 1 and 2). Therefore, the elimination of contaminated organic substrates is indispensable especially when the concentration of DCP is low. We eliminated more than $99.9 \%$ of contaminated organic substrates by using heterotrophic microorganisms, since the density of DP-4 without DCP was almost constant at less than $10^{3} \mathrm{cell} / \mathrm{ml}$ (Figs. 2 and 3). The heterotrophic microorganisms used in this study seemed not to affect the growth or activities of DP-4 except for the elimination of contaminated organic substrates. We propose that the method applied in this study is effective and simple to eliminate contaminated organic substrates and to estimate kinetic parameters of microorganisms in vitro.

The amount of contaminated organic substrates in synthetic liquid media was reported to be $2^{4)}$, $0.1^{9)}$ or from 0.1 to $1 \mu \mathrm{g} / \mathrm{ml}^{12)}$ in terms of carbon amount, and the density of microorganisms at the early stage of the stationary phase was $10^{7}, 10^{5}$, or from $10^{5}$ to $10^{6} \mathrm{cell} / \mathrm{ml}$, respectively. In this study, the amount of contaminated organic substrates estimated from Fig. 4 were nutritionally equivalent to ca. $2 \mu \mathrm{g}$ DCP-C $/ \mathrm{ml}$ which was enough for microorganisms to increase their density to $10^{6} \mathrm{cell} / \mathrm{ml}$.

Nevertheless, Monod ${ }^{8)}$, or Harder and Veldkamp ${ }^{5}$ reported the specific growth rate of Escherichia coli or Pseudomonas sp. assimilating glucose or lactate without discussing the possibility of contaminated organic substrates. Therefore, the accuracy of the specific growth rates reported by them are questionable.

Deviation from the proportional relationship between initial concentrations of DCP and the densities of DP-4 in the early stationary phase in the presence of heterotrophic microorganisms (Fig. 4) may be due to the experimental errors especially associated with MPN method, co-metabolism or toxicity of DCP. The MPN method has a low order of precision ${ }^{1)}$. In a 10 -fold dilution, the lower and upper limit for $95 \%$ confidence limits are $4.68^{-1}$ and 4.68 times the MPN values estimated, respectively. Deviation from the proportional 
relationship at densities of DP-4 as low as $0.1 \mu \mathrm{g}$ $\mathrm{DCP}-\mathrm{C} / \mathrm{ml}$ may be co-metabolism ${ }^{6}$, i.e., the degradation of chemicals without deriving energy or carbon for microbial growth. The lower density of DP-4 (Fig. 4) or lower specific growth rate (Fig. 5) at $10 \mu \mathrm{g} \mathrm{DCP}-\mathrm{C} / \mathrm{ml}$, both in the absence and presence of heterotrophic microorganisms may be attributable to the toxicity of DCP, a microbicide, normally effective at concentration as high as 10 $\mu \mathrm{g} \mathrm{DCP}-\mathrm{C} / \mathrm{ml}$.

To estimate the rate of biodegradation of xenobiotics in natural aquatic environments, we may predict the biodegradation by using kinetic parameters obtained in the laboratory. Generally, the concentration of xenobiotics are extremely low, less than $0.1 \mu \mathrm{g} / \mathrm{ml}$ in natural aquatic environments, such as ocean, stream or ground water ${ }^{3,14)}$, and microorganisms of interest are accompanied by other heterotrophic microorganisms. Therefore, the method applied in this study may reflect more closely the kinetic parameters for the estimation of the biodegradation of xenobiotics in natural aquatic environments.

\section{References}

1) Alexander, M., in "Methods of Soil Analysis, Part 2. Chemical and Microbiological Properties", American Society of Agronomy, Wisconsin, 1982, pp. 815-820.

2) Button, D.K. 1985 . Kinetics of nutrientlimited transport and microbial growth. Microbiological Rev. 49: 270-297.

3) Frank, R., B.S. Clegg, C. Sherman and N.D. Chapman, 1990. Triazine and chloroacetamide herbicides in Sydenham River water and municipal drinking water, Dresden Ontario, Canada, 1981-1987. Arch. Environ. Contam. Toxicol.
19: $319-324$

4) Geller, A. 1983. Growth of bacteria in inorganic medium at different levels of airborne organic substances. Appl. Environ. Microbiol. 46: 1258-1262.

5) Harder, W. and H. Veldkamp. 1971. Competition of marine psychlophilic bacteria at low temperatures. Antonie van Leeuwenhoek. 37 : 51-63.

6) Horvath, R.S. 1972. Microbial co-metabolism and the degradation of organic compounds in nature. Bacteriol. Rev. 36: 146-155.

7) Konings, W.N. and H. Veldkamp, in "Contemporary Microbial Ecology", ed. by. D.C. Ellwood, J.N. Hedger, J.M. Lynch and J.H. Slater. Academic Press, New York, 1980, pp. 161-191.

8) Monod, J. 1949. The growth of bacterial cultures. Ann. Rev. Microbiol. 3: 371-394.

9) Seto, M. and M. Alexander. 1985. Effect of bacterial density and substrate concentration on yield coefficients. Appl. Environ. Microbiol. 50 : 1132-1136.

10) Seto, M., K. Ikejima and S. Nakano. 1989. Some observations on the density of chlorophenol-degrader and the degradation of chlorophenol in water sample from the river Tamagawa. Man \& Environ. 14: 12-19. (in Japanese)

11) Seto, M. and F. Tsurui. 1989. Survival of 2, 4-dichlorophenol (DCP)-degraders and their expression of DCP-degrading activity in water samples from aquatic environment. Man \& Environ. 15: 18-24. (in Japanese)

12) Seto, M., Y.Tanaka, T. Homma and A. Yamasaki. 1992. Degradation of 2, 4-dichlorophenol at low concentration and biomass production by microorganisms. Man \& Environ. $18: 15-20$. (in Japanese)

13) Slater, J.H. in "Microbial Ecology", ed. by J.M. Lynch and N.J. Poole. Blackwell Scientific Publications, Oxford, 1979, pp. 45-63.

14) Takada, H. 1993. Distributions and behavior of surfactants and related products in aquatic environments. J. Japan Sci. Water Environ. 16: 308-313. (in Japanese) 